\title{
Relieving dyspnoea by non-invasive ventilation decreases pain thresholds in amyotrophic lateral sclerosis
}

\author{
Laurence Dangers, ${ }^{1,2}$ Louis Laviolette, 1,3 Marjolaine Georges, 1,2 \\ Jésus Gonzalez-Bermejo, ${ }^{1,2}$ Isabelle Rivals, ${ }^{1,4}$ Thomas Similowski, 1,2 \\ Capucine Morelot-Panzini ${ }^{1,2}$
}

\begin{abstract}
${ }^{1}$ Sorbonne Universités, UPMC Univ Paris 06, INSERM, UMRS1158 Neurophysiologie respiratoire expérimentale et clinique, Paris, France

${ }^{2}$ Groupe Hospitalier PitiéSalpêtrière Charles Foix, Service de Pneumologie et

Réanimation Médicale (Département 'R3S'), AP-HP,

Paris, France

${ }^{3}$ Centre de recherche de

I'Institut Universitaire de Cardiologie et de Pneumologie de Québec (CRIUCPQ), Québec, Canada

${ }^{4}$ Ecole Supérieure de Physique et de Chimie de la Ville de Paris, Paris, France
\end{abstract}

\section{Correspondence to}

Dr Capucine Morélot-Panzini, Groupe Hospitalier Pitié-

Salpêtrière Charles Foix, Service de Pneumologie et

Réanimation Médicale

(Département 'R3S'), AP-HP,

47-83 Bd de l'Hôpital 75651

Paris Cedex 13, Paris F-75013,

France;

capucine.morelot@psl.aphp.fr

TS and CM-P are co-last authors.

Received 26 February 2016 Revised 11 July 2016 Accepted 16 July 2016 Published Online First 9 August 2016

\begin{abstract}
Background Dyspnoea is a threatening sensation of respiratory discomfort that presents many similarities with pain. Experimental dyspnoea in healthy subjects induces analgesia. This 'dyspnoea-pain counter-irritation' could, in reverse, imply that relieving dyspnoea in patients with chronic respiratory diseases would lower their pain thresholds.

Methods We first determined pressure pain thresholds in 25 healthy volunteers (22-31 years; 13 men; handheld algometer), during unloaded breathing (BASELINE) and during inspiratory threshold loading (ITL). Two levels of loading were used, adjusted to induce dyspnoea self-rated at $60 \%$ or $80 \%$ of a $10 \mathrm{~cm}$ visual analogue scale (ITL6 and ITL8). 18 patients with chronic respiratory failure due to amyotrophic lateral sclerosis (ALS) were then studied during unassisted breathing and after 30 and 60 min of non-invasive ventilation —NIV30 and NIV60-(same dyspnoea evaluation).
\end{abstract}

Results In healthy volunteers, pressure pain thresholds increased significantly in the deltoid during ITL6 $(p<0.05)$ and ITL8 $(p<0.05)$ and in the trapezius during ITL8 $(p<0.05)$, validating the use of pressure pain thresholds to study dyspnoea-pain counter-irritation. In patients with ALS, the pressure pain thresholds measured in the deltoid during unassisted breathing decreased by a median of $24.5 \%-33.0 \%$ of baseline during NIV30 and NIV60 ( $p<0.05)$.

Conclusion Relieving dyspnoea by NIV in patients with ALS having respiratory failure is associated with decreased pressure pain thresholds. Clinical implications have yet to be determined, but this observation suggests that patients with ALS could become more susceptible to pain after the institution of NIV, hence the need for reinforced attention towards potentially painful diagnostic and therapeutic interventions.

\section{INTRODUCTION}

Dyspnoea is a threatening sensation of respiratory CrossMark

\section{To cite: Dangers $L$,} Laviolette L, Georges M, et al. Thorax 2017;72:230235. discomfort that is accompanied by negative emotions and autonomic manifestations. ${ }^{1}$ It is therefore similar to pain, to which it is sometimes compared by patients with chronic respiratory diseases ('my breathing is painful') and with which it shares common neural networks ${ }^{2}$ that comprise the insula among other structures including the cerebellum,

\section{Key messages}

What is the key question?

- Suffering from dyspnoea decreases the perception of pain; does the treatment of dyspnoea make patients more susceptible to pain?

What is the bottom line?

- Non-invasive ventilation decreases the pain threshold in patients with chronic respiratory insufficiency due to amyotrophic lateral sclerosis, a neuromuscular disorder.

\section{Why read on?}

- Initiating non-invasive ventilation with the objective of alleviating dyspnoea should be associated with increased awareness to pain and its management.

anterior cingula and amygdala. ${ }^{3}$ Among dyspnoeapain similarities, dyspnoea can attenuate pain in a counter-irritation-like manner (dyspnoea-pain counter-irritation). This has been described for various modalities of pain (heat pain, cold-pressure pain, ischaemic pain) and various modalities of dyspnoea (air hunger sensation, sensation of excessive inspiratory effort). ${ }^{5-7}$ Neurophysiologically, dyspnoea has an inhibitory effect on brain potentials evoked by painful laser stimulation of the skin (commonly referred to as laser-evoked potentials), leading to the hypothesis of a dyspnoea-pain competition at common cortical networks. ${ }^{8} 9$ Experimental dyspnoea of the 'excessive effort' type also has a potent inhibitory effect on the nociceptive spinal flexion reflex, ${ }^{10}$ suggesting activation of diffuse nociceptive inhibitory controls and leading to the hypothesis that respiratory muscle C-fibres ${ }^{11}$ are involved in the pathogenesis of 'work/effort' dyspnoea. ${ }^{10}$

To date, dyspnoea-pain counter-irritation has only been described during experimental studies in healthy volunteers. Its clinical relevance in patients with chronic respiratory diseases is unknown. In such patients, dyspnoea is often the foremost symptom, invading consciousness and making life 
miserable. Consequently, relief of dyspnoea constitutes a priority of clinical management in these patients and can be achieved by correcting the underlying respiratory abnormalities or by administrating opiates when correction of respiratory abnormalities is impossible or is not sufficient. ${ }^{12}$ In patients who experience dyspnoea due to respiratory muscle weakness, mechanical ventilatory assistance provides profound and rapid relief. ${ }^{13}$ In amyotrophic lateral sclerosis (ALS), this effect on dyspnoea is considered to be a major benefit of non-invasive ventilation (NIV) ${ }^{14}$ Based on the observation that experimental dyspnoea attenuates pain, we hypothesised that relieving an existing clinical dyspnoea could lower pain thresholds and therefore could make patients more susceptible to pain. We tested this hypothesis in patients with ALS having respiratory failure treated with NIV by studying the associations between NIV-induced dyspnoea relief and changes in pressure pain thresholds determined by means of a handheld algometer. ${ }^{15}{ }^{16}$ Because there were no published data on the modulation of pressure pain thresholds by dyspnoea in the dyspnoea-pain literature, we conducted a preliminary proof of concept study in healthy volunteers to verify that dyspnoea-pain counter-irritation could be evidenced by this approach.

\section{MATERIAL AND METHODS Ethics}

This study was conducted according to the principles of the Declaration of Helsinki; it was approved by the appropriate French legal and ethical external review board (Comité de Protection des Personnes Ile-de-France 6, La Pitié-Salpêtrière). All participants (patients and healthy volunteers) were informed in detail about the study objectives and the methods used and all provided their written informed consent.

\section{Part one: healthy volunteers}

Twenty-five healthy volunteers (median age 27, IQR (23-30); 12 women; median body mass index $\left.22 \mathrm{~kg} / \mathrm{m}^{2},(21-22.5)\right)$ were included. They were asked not to take any analgesics, nonsteroidal anti-inflammatory drugs, corticosteroids or psychotropic agents during the 48 hours prior to the study.

\section{Recording of ventilatory variables}

Subjects wore a nose clip and breathed through a leakproof mouthpiece. Ventilatory flow rate was recorded by a pneumotachograph. Oral pressure was measured by a pressure transducer connected to the mouthpiece in 14 of the 25 subjects. Signals were digitised at a frequency of $200 \mathrm{~Hz}$ (Powerlab, ADInstruments, Castle Hill, Australia) and analysed using dedicated software (Labchart (V.7.2.3), ADInstruments, Castle Hill, Australia).

\section{Induction and evaluation of dyspnoea}

Dyspnoea was induced by inspiratory threshold loading (ITL) (PowerBreathe, Sissel, Sweden), connected in series to the ventilatory measuring device. The intensity of loading was initially adjusted to obtain respiratory discomfort rated between 50\% and $70 \%$ of full scale on an electronic visual analogue scale scored from 0\% (in French pas de gêne respiratoire du tout, meaning 'no respiratory discomfort at all') to $100 \%$ (pire gêne respiratoire que vous pouvez imaginer, meaning 'worst respiratory discomfort that you can imagine') ('ITL6' condition). The level of respiratory discomfort was then increased by increasing inspiratory loading to obtain respiratory discomfort rated between $70 \%$ and $90 \%$ of full scale on the visual analogue scale
('ITL8' condition). The order of ITL6 and ITL8 conditions was not randomised.

Determination of the pressure pain thresholds

Subjects were seated in an examination chair with their nondominant arm along the body and the forearm in extension and supination. The central portions of the biceps, deltoid and trapezius muscles were marked with a felt pen. Pressure pain thresholds were evaluated by means of a handheld algometer (Force One, Wagner Instruments, Greenwich, Connecticut, USA). The algometer was applied perpendicularly to the muscle tested at the previously identified site, with the measuring cursor not visible to the subject and the first examiner for all 25 subjects. ${ }^{17}$ The second examiner recorded the pressure pain threshold values corresponding to the force per unit surface area necessary to induce the difference between a feeling of simple pressure and a painful sensation. Standardized instructions were given to the subjects: 'raise the hand opposite to the tested arm as soon as the feeling changes from a feeling of simple pressure to a painful feeling and I will stop the stimulation'. Subjects were trained in this difference before starting the experiment by testing on the contralateral arm. In each of the respiratory conditions evaluated (unloaded breathing - 'BASELINE' - and the two levels of inspiratory loading, ITL6 and ITL8), three measurements were performed at each site and pressure pain threshold was calculated as the mean of these three measurements.

\section{Part two: patients with ALS}

Eighteen patients (median age: 69 years; IQR (63-75); 4 women) managed in a day-care unit specialised in home ventilatory assistance within a university hospital respiratory medicine department were included. All patients had a confirmed or probable diagnosis of ALS according to the revised El Escorial criteria. ${ }^{18}$ The median time since diagnosis of ALS was 1.56 years (IQR $(0.97-2.08)$ ). All patients were treated by NIV due to ALS respiratory muscle weakness, according to current recommendations. ${ }^{19}$ All patients experienced dyspnoea at rest. Sixteen of them reported a worsening of their resting dyspnoea with recumbent posture (orthopnoea). Median $\mathrm{PaO}_{2}$ was $80 \mathrm{~mm} \mathrm{Hg}$ (76-94) during unassisted breathing in room air with a median $\mathrm{PaCO}_{2}$ of $44 \mathrm{~mm} \mathrm{Hg}$ (41-47). The median interval since initiation of NIV was 9.2 months (8.5-17.5). The median daily duration of ventilation, using a bi-level positive airway pressure mode, was 12 hours (8.5-13.7), with a minimal duration of 6 hours and a maximal duration of 16 hours. Patients were evaluated at routine visits designed to assess the quality of NIV and their clinical management was not modified in any way for the study.

\section{Psychosensory assessments}

The patients' respiratory discomfort was evaluated by a visual analogue scale scored from $0 \%$ (no respiratory discomfort at all) to $100 \%$ (maximum respiratory discomfort that you can imagine). The patients' anxiety and 'general' pain were also measured by visual analogue scale from $0 \%$ (no anxiety, no pain) to $100 \%$ (maximum anxiety, intolerable pain). These variables were evaluated under three respiratory conditions: BASELINE: unassisted breathing; NIV30: after $30 \mathrm{~min}$ of NIV and NIV60: after 60 min of NIV. NIV was delivered with the patient's usual ventilator and interface with no modification of the usual parameters. The baseline sensory and affective dimensions of dyspnoea were described by means of the Multidimensional Dyspnea Profile (MDP). ${ }^{20}$ In brief, the MDP 
consists of one item (A1) that assesses the unpleasantness of dyspnoea on a $0-10$ visual numerical scale, five items (S) that assess the sensory dimension of dyspnoea (choice of a principal descriptor and 0-10 evaluation of each of the five) and five items (A2) that assess the affective dimension of dyspnoea. We calculated an 'immediate perception domain score' $\mathrm{S}$ as the sum of A1 and of the ratings of the five sensory descriptors and an 'emotional response domain score' as the sum of the ratings of the five affective descriptors. ${ }^{20} 21$

\section{Determination of pressure pain thresholds}

The procedure was strictly identical to that described above for healthy volunteers. Algometric measurements were performed under three respiratory conditions: BASELINE, NIV30 and NIV60.

\section{Statistics}

All statistical analyses were performed with Graphpad Prism (V.5.0) software (Graphpad Software, USA) and SPSS (V.22.0; IBM, Armonk, New York, USA). All values are expressed as median and IQR, irrespective of the nature of data distribution. Two-by-two comparisons between BASELINE, ITL6 and ITL8 in the healthy volunteers and between BASELINE, NIV30 and NIV60 in patients with ALS were conducted using Wilcoxon signed-rank test, with use of Bonferroni's correction for multiple testing. A p value below 0.05 (after Bonferroni's correction) was considered to be statistically significant.

\section{RESULTS}

\section{Part one: healthy volunteers}

None of the subject reported respiratory discomfort at baseline. The intensity of respiratory discomfort induced by inspiratory loading is depicted in figure 1 that shows that the predefined experimental objectives were actually reached for both ITL6 and ITL8, with pressures measured at the mouthpiece (14 subjects) of $22 \mathrm{cmH}_{2} \mathrm{O}(15-29.5)$ at ITL6 and $27.2 \mathrm{cmH}_{2} \mathrm{O}(19.7-34)$ at ITL8. ITL was associated with a tendency of partial pressure of end-tidal carbon dioxide to decrease $(42 \mathrm{~mm} \mathrm{Hg}(39-44)$ at BASELINE (14 subjects), $40 \mathrm{~mm} \mathrm{Hg}$ (38-44) (non significant, NS) at ITL6 and 39 (32-42) at ITL8 (NS), probably in line with the hyperventilation that is usually observed in response to ITL. ${ }^{22}$

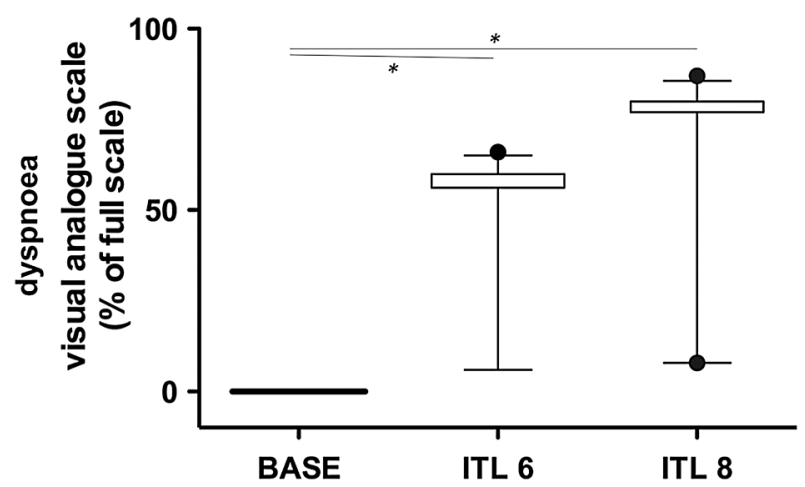

Figure 1 Self-assessment of dyspnoea using a visual analogue scale in healthy volunteers during unloaded breathing (BASELINE) and inspiratory threshold loading (ITL) adjusted to induce dyspnoea with a visual analogue scale score of $60 \%$ (ITL6) or $80 \%$ of full scale (ITL8). The boxes delineate the IQR, with indication of the median. The whiskers correspond to the 95th percentile of the distribution. The black circles correspond to outliers. ITL was successful in inducing dyspnoea except in a few subjects.
Table 1 Pain pressure thresholds in healthy volunteers according to experimental conditions

\begin{tabular}{|c|c|c|c|}
\hline \multicolumn{4}{|c|}{ Pain pressure threshold- $\mathrm{N} / \mathrm{cm}^{2}$} \\
\hline & Deltoid & Biceps brachii & Trapezius \\
\hline \multicolumn{4}{|l|}{ Unloaded breathing } \\
\hline Baseline $n=25$ & $27.9(23-42.6)$ & $20.6(17.8-32.5)$ & $24.3(16.5-31.1)$ \\
\hline \multicolumn{4}{|l|}{ ITL } \\
\hline ITL6 $n=25$ & $34.2(24.1-48.3)$ & $21.3(16.5-34.5)$ & $25.1(20.2-33.2)$ \\
\hline ITL8 n=25 & $37(26.6-48)$ & $26.3(19.6-32.8)$ & $25.4(20.4-32.4)$ \\
\hline \multicolumn{4}{|c|}{ Two-by-two comparisons } \\
\hline Baseline vs ITL6 & $p=0.037$ & $p=1$ & $p=0.32$ \\
\hline Baseline vs ITL8 & $p=0.003$ & $\mathrm{p}=0.35$ & $p=0.037$ \\
\hline IL6 vs ITL8 & $p=0.2$ & $p=0.52$ & $p=0.26$ \\
\hline
\end{tabular}

Values are expressed as medians (IQR).

$\mathrm{p}$ Values are provided after Bonferonni's correction

ITL, inspiratory threshold loading; ITL6, ITL adjusted to induce dyspnoea scored as $50 \%-70 \%$ of full scale on the visual analogue scale; ITL8, ITL adjusted to induced dyspnoea scored as $70 \%-90 \%$ of full scale on the visual analogue scale.

The pressure pain thresholds recorded for the three muscles in the three conditions are reported in table 1.

The analysis of within-subject changes in pressure pain threshold (normalised for baseline) showed that under the ITL6 condition, pressure pain threshold was significantly increased in the deltoid $(10 \%(-7$ to 36$))(p=0.037)$. The same was true under the ITL8 condition for the deltoid $(18 \%(2.3-51.7)(\mathrm{p}=0.027)$ and for the trapezius (10\% (-5.7 to 36.4$))$. No significant difference in pressure pain threshold was observed between ITL 6 and ITL8 for the deltoid, biceps and trapezius muscles.

\section{Part two: patients with ALS}

The intensity of respiratory discomfort self-reported by the patients while breathing without assistance is described in figure 2, together with the intensity of anxiety. Of the 18 patients, 15 filled the MDP questionnaire (two were not sufficiently fluent in French, one refused because the patient was too tired). The main sensory descriptor was 'physical effort' in six cases, 'air hunger' in five cases, 'chest constriction' in three cases and 'hyperpnoea' in one case. All the patients chose three or more descriptors as relevant to the description of their dyspnoea. The median immediate perception domain score was 29 (19.2-38) and the median emotional response domain was $17(10.8-25.0)$ (values similar to previously published ones in comparable patients with $\mathrm{ALS}^{23}$ ).

Respiratory discomfort decreased dramatically in response to NIV30 and NIV60 ( $p<0.001$ in both cases) (figure 2), which was concomitant with a near disappearance of anxiety (figure 2). Of notice, median $\mathrm{PaCO}_{2}$ tended to be lower during NIV $(41 \mathrm{~mm} \mathrm{Hg}$ $(38-45))$ than during unassisted breathing $(44 \mathrm{~mm} \mathrm{Hg}$ (41.247.4)) $(\mathrm{p}=0.5)$.

The pressure pain thresholds recorded for the three muscles under the three study conditions are reported in table 2.

The analysis of within-subject changes in pressure pain threshold (normalised for baseline) showed that pressure pain threshold decreased significantly in the deltoid during NIV30 $(-24.5 \%(-14.7$ to 29.7$))(p=0.047)$ and NIV60 $(-33.0 \%$ $(-21.0$ to 38.3$)) \quad(\mathrm{p}=0.011)$ compared with BASELINE. Pressure pain thresholds for the biceps decreased significantly during NIV30 (-23.1\% ( -14.0 to 34.0$))(p=0.037)$. Pressure pain thresholds was significantly decreased in the trapezius during NIV30 $(-6.0 \%(-19.0$ to 2.75$))(\mathrm{p}=0.047)$ and NIV60 $(-16.5 \%(-26.0$ to 3.0$))(\mathrm{p}=0.027)$. 

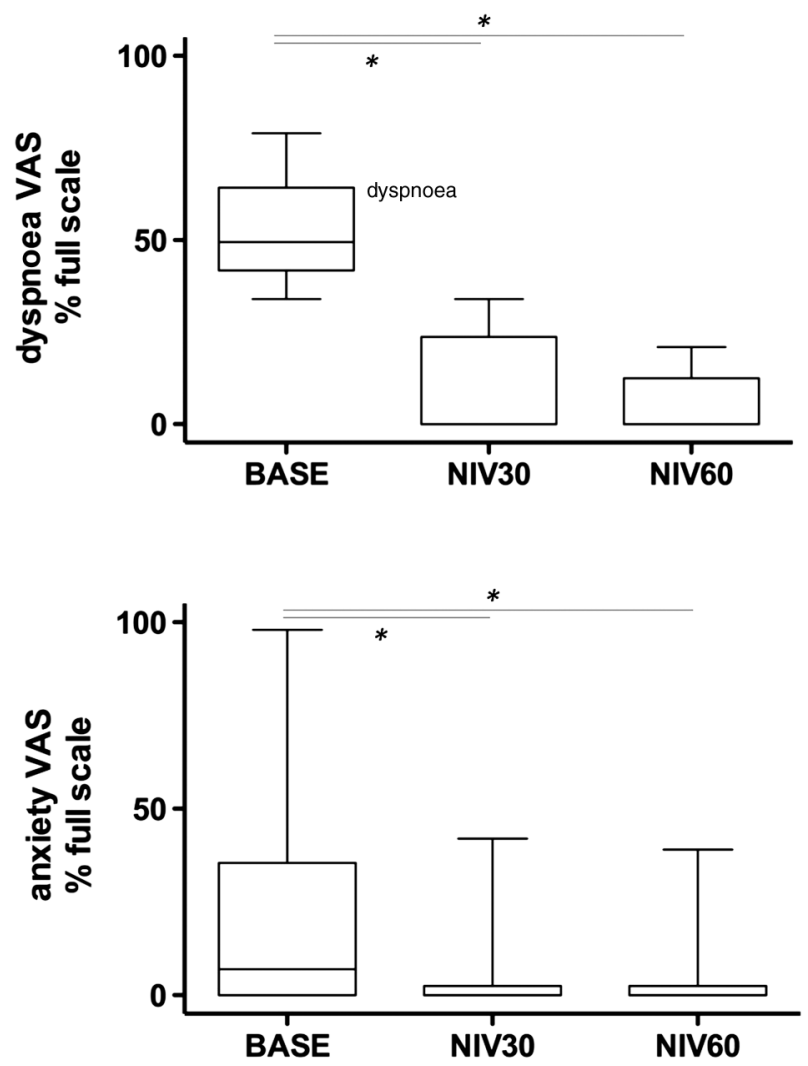

Figure 2 Self-assessment of dyspnoea (top) and anxiety (middle) using visual analogue scales (VAS) in patients with amyotrophic lateral sclerosis and related chronic respiratory failure, during unassisted breathing (BASELINE) and non-invasive ventilation (NIV) after $30 \mathrm{~min}$ (NIV30) and after 60 min (NIV60). The boxes delineate the IQR, with indication of the median. The whiskers correspond to the 95th percentile of the distribution. The ${ }^{\prime * \prime}$ symbol denotes a significant difference with $p<0.05$. NIV was successful in relieving dyspnoea and was associated with reduced anxiety.

\section{DISCUSSION}

This study mainly shows that relieving dyspnoea by NIV in patients with ALS rapidly decreases their pressure pain threshold. This suggests that in these patients dyspnoea associated with respiratory insufficiency might decrease the susceptibility to pain when they are not under NIV.

\section{Proof of concept study in healthy subjects}

Clinical assessment of dyspnoea-pain interactions requires easy-to-use, reproducible, bedside pain evaluation that is not exceedingly unpleasant for the patient. Pressure pain threshold determination using a handheld algometer meets these criteria $^{15}{ }^{17}$ but it has not been specifically studied how experimental dyspnoea modifies this measure..$^{5-7} 24$ In addition, not all modalities of dyspnoea interfere with all pain modalities in the same way (eg, hypercapnia, an air hunger-inducing stimulus, attenuates heat pain and ischaemic pain, but not pressure pain or electric pain ${ }^{5}$ ). Before studying whether and how relief of dyspnoea by NIV in patients with ALS can modify pressure pain thresholds, it is therefore important (if only for ethical reasons) to verify the suitability of the algometer approach with regard with dyspnoea-pain counter-irritation in healthy subjects. Of note, our healthy subjects were studied for proof of concept purpose, not as a control group.
We used ITL mostly because its effects on various neurophysiological substrates of the dyspnoea-pain counter-irritation have been previously described. ${ }^{9}{ }^{10}$ Also, and in contrast with inspiratory resistive loading, ITL makes it impossible for the subject to avoid the load-related effort by altering breathing pattern: this resembles what patients with weak inspiratory muscles experience. Our finding that ITL-induced dyspnoea increases pain thresholds is consistent with dyspnoea-pain counter-irritation and provides a perceptual counterpart to previously reported neurophysiological data. ${ }^{9}{ }^{10}$ As in any counterirritation study, it is important to emphasise that attentional effects can contribute to the attenuation of pain. Conceptually, this type of effects could be more marked in dyspnoea-pain counter-irritation studies because of the threatening nature of the pain-attenuating stimulus. Attentional effects cannot be ruled out in our study, even though to minimise such effects on identification of pressure pain thresholds, we asked our subjects to concentrate on the painful stimulus, ${ }^{25}$ a technique that is also used to control attentional effects in laser-evoked potential studies. ${ }^{9}$ However, mental concentration alone can fail to elicit pain attenuation ${ }^{10}$ and there is evidence in the pain literature that counter-irritation acts independently from distraction. ${ }^{26}$

The pressure pain threshold values in our healthy subjects were within the expected range. ${ }^{15}{ }^{17}$ With reference to baseline values, the percentages of dyspnoea-related increases in pressure pain thresholds was consistent with previous 'classical' counterirritation studies. ${ }^{27} 28$ In absolute terms, these changes were similar to those observed after the administration of a clinically relevant dose of morphine $\left(0.7-9.1 \mathrm{~N} / \mathrm{cm}^{2}\right.$ in our subjects, vs 2.35 to $8.04 \mathrm{~N} / \mathrm{cm}^{2}$ in a study by Kindler et $a l^{29}$ ). Of note, there was a wide inter-individual variance in behaviour, with some subjects even responding in direction opposite to the mean in terms of pressure pain thresholds (see Results section). This is not unexpected in view of the nature of the studied outcomes, but of note was mostly observed in the small number of subjects where ITL failed to reach the pre-assigned objectives in terms of dyspnoea (figure 1).

\section{Clinical study in patient with ALS}

The decrease in pressure pain thresholds that accompanied NIV-induced relief of dyspnoea in our patients mirrors the dyspnoea-pain counter-irritation phenomenon. It is reminiscent of pain counter-irritation studies during which withdrawal of the heterotopic noxious stimulation restores the response to the original pain ${ }^{3031}$ and suggests an analgesic effect of ALS-related dyspnoea. To our knowledge, this is the first time that this phenomenon has been described for 'clinical dyspnoea' (as opposed to 'experimental dyspnoea)'. Our findings also indicate that the analgesic effect of dyspnoea is probably not transient but persists in the long term. Of importance, NIV lowered $\mathrm{PaCO}_{2}$, which, given the known analgesic effects of hypercapnia, ${ }^{3}$ could have contributed to our observations. However the magnitude of $\mathrm{PaCO}_{2}$ variations known to induce analgesia is far greater than those measured in our patients. As in the case of our healthy subjects, the changes in pressure pain thresholds during NIV were roughly within the range of those observed in response to morphine (1.85 to $5.2 \mathrm{~N} / \mathrm{cm}^{2}$ in our patients vs 2.35 to $8.04 \mathrm{~N} / \mathrm{cm}^{2}$ in a study of normal subjects by Kindler et $\left.a l^{29}\right)$. Also as in the normal subjects, there was a wide interindividual variance in the patients.

From a physiological point of view, respiratory failure in ALS involves diaphragmatic dysfunction and compensatory recruitment of extra-diaphragmatic inspiratory muscles including neck muscles. $^{32} 33$ Recent data suggest that this recruitment could 
Table 2 Pain pressure thresholds in patients with amyotrophic lateral sclerosis according to experimental conditions

\begin{tabular}{|c|c|c|c|}
\hline \multicolumn{4}{|c|}{ Pain pressure thresholds- $\mathrm{N} / \mathrm{cm}^{2}$} \\
\hline & Deltoid & Biceps brachii & Trapezius \\
\hline \multicolumn{4}{|l|}{ Unassisted breathing } \\
\hline Baseline $n=18$ & $21.40(18.05-32.43)$ & $18.50(15.68-24.25)$ & $15.95(14.13-20.83)$ \\
\hline \multicolumn{4}{|l|}{ NIV } \\
\hline NIV30 $n=18$ & $17.85(13.75-24.40)$ & $14.45(10.83-18.60)$ & $14.10(11.85-20.63)$ \\
\hline NIV60 $n=18$ & $16.35(11.88-21.90)$ & $13.30(10.45-15.23)$ & $13.25(10.35-19.95)$ \\
\hline \multicolumn{4}{|c|}{ Two-by-two comparisons } \\
\hline Baseline vs NIV30 & $p=0.011$ & $p=0.003$ & $p=0.26$ \\
\hline Baseline vs NIV60 & $\mathrm{p}<0.001$ & $p<0.001$ & $p=0.037$ \\
\hline NIV30 vs NIV60 & $p=0.037$ & $\mathrm{p}=0.037$ & $p=0.15$ \\
\hline
\end{tabular}

result from the activation of respiratory-related cortical networks. $^{23}$ As in the case of most clinical dyspnoeas, the ALS-related dyspnoea is bound to be multifactorial, possibly involving the increased drive to breathe and its cortical component, ${ }^{23}$ low lung volumes and other factors. Among those, our results suggest that $\mathrm{C}$ fibres (bronchopulmonary or muscular) and/or myelinated ad fibres could also play a role because counter-irritation specifically involve these fibres.

\section{Clinical implications and perspectives}

Although ALS is a degenerative disorder affecting motor neurones, patients with ALS often report pain ${ }^{34} 35$ that contributes to their poor quality of life. ${ }^{36} 37$ It is a neglected aspect of this disease, ${ }^{38}$ as illustrated by the dearth of specific clinical trials. ${ }^{39}$ The two populations reported in the present study are very different (different age, normal muscles in the healthy subjects versus atrophied muscles in the patients, etc) and were subjected to opposite interventions. This precludes any reasonable comparison between the two groups, which was not intended in the study design (see 'proof of concept study in healthy subjects' section). Yet one cannot fail to remark that baseline pressure pain thresholds were lower in our patients than in our healthy subjects in spite of their older age, ${ }^{40}$ which is probably an additional incentive to pay attention to pain in patients with ALS in a general manner.

More specifically, and even though the clinical translation of our findings will have to be specifically investigated, the fact that pressure pain thresholds were lower during NIV than during unassisted breathing in our patients raises a relevant issue. It is indeed possible that placing patients with ALS under NIV to correct hypoventilation and alleviate dyspnoea makes them more susceptible to pain, for example, during medical interventions like gastrostomy tube insertion or merely during simple daily care (eg, positioning in paralysed patients). This should obviously not make physicians reluctant to initiate NIV when indicated but is a strong incentive to further raise awareness to pain after NIV initiation.

\section{Acknowledgements The authors are grateful to Anthony Saul, professional} medical editor, for his help with English style and grammar.

Contributors $L D, L L, T S$ and $C M-P$ conceived the study design and the experimental plan. LD, LL, MG, JG-B, CM-P contributed to data acquisition and analysis. LD, CM-P and TS drafted and elaborated the manuscript. IR supervised the statistical analysis. All authors contributed to the final version of the manuscript and approved it.
Funding Study was supported by the non-profit Association pour le Développement et l'Organisation de de la Recherche en Pneumologie et sur le Sommeil, a grant Legs Poix from the Chancellerie de I'Université de Paris, Paris, France' and by the programme 'Investissement d'Avenir ANR-10-AlHU 06' of the French Government.

Competing interests None declared.

Ethics approval Comité de Protection des Personnes Ile-de-France 6, La Pitié-Salpêtrière.

Provenance and peer review Not commissioned; externally peer reviewed.

\section{REFERENCES}

1 Parshall MB, Schwartzstein RM, Adams L, et al. An official American Thoracic Society statement: update on the mechanisms, assessment, and management of dyspnea. Am J Respir Crit Care Med 2012;185:435-52.

2 von Leupoldt A, Sommer T, Kegat $S$, et al. Dyspnea and pain share emotion-related brain network. Neuroimage 2009:48:200-6.

3 Banzett RB, Mulnier HE, Murphy K, et al. Breathlessness in humans activates insular cortex. Neuroreport 2000;11:2117-20.

4 Peiffer C, Poline JB, Thivard L, et al. Neural substrates for the perception of acutely induced dyspnea. Am J Respir Crit Care Med 2001;163:951-7.

5 Grönroos M, Pertovaara A. A selective suppression of human pain sensitivity by carbon dioxide: central mechanisms implicated. Eur J Appl Physiol Occup Physiol 1994;68:74-9.

6 Nishino $T$, Isono S, Ishikawa $T$, et al. Sex differences in the effect of dyspnea on thermal pain threshold in young healthy subjects. Anesthesiology 2008;109:1100-6.

7 Yashiro E, Nozaki-Taguchi N, Isono S, et al. Effects of different forms of dyspnoea on pain perception induced by cold-pressor test. Respir Physiol Neurobiol 2011;177:320-6.

8 Dangers L, Laviolette L, Similowski T, et al. Interactions between dyspnea and the brain processing of nociceptive stimuli: experimental air hunger attenuates laser-evoked brain potentials in humans. Front Physiol 2015;6:358.

9 Bouvier G, Laviolette L, Kindler F, et al. Dyspnea-pain counterirritation induced by inspiratory threshold loading: a laser-evoked potentials study. J Appl Physiol (1985) 2012;112:1166-73.

10 Morélot-Panzini C, Demoule A, Straus C, et al. Dyspnea as a noxious sensation: inspiratory threshold loading may trigger diffuse noxious inhibitory controls in humans. J Neurophysiol 2007;97:1396-404.

11 Villanueva L, Le Bars D. The activation of bulbo-spinal controls by peripheral nociceptive inputs: diffuse noxious inhibitory controls. Biol Res 1995;28:113-25.

12 Currow DC, Ekstrom M, Abernethy AP. Opioids for chronic refractory breathlessness: right patient, right route? Drugs 2014;74:1-6.

13 Hannan LM, Dominelli GS, Chen YW, et al. Systematic review of non-invasive positive pressure ventilation for chronic respiratory failure. Respir Med 2014;108:229-43.

14 Tripodoro VA, De Vito EL. Management of dyspnea in advanced motor neuron diseases. Curr Opin Support Palliat Care 2008:2:173-9.

15 Fischer AA. Pressure algometry over normal muscles. Standard values, validity and reproducibility of pressure threshold. Pain 1987;30:115-26.

16 Nussbaum EL, Downes L. Reliability of clinical pressure-pain algometric measurements obtained on consecutive days. Phys Ther 1998;78:160-9.

17 Antonaci F, Sand T, Lucas GA. Pressure algometry in healthy subjects: inter-examiner variability. Scand J Rehabil Med 1998;30:3-8. 
18 Brooks BR, Miller RG, Swash M, et al., World Federation of Neurology Research Group on Motor Neuron Diseases. El Escorial revisited: revised criteria for the diagnosis of amyotrophic lateral sclerosis. Amyotroph Lateral Scler Other Motor Neuron Disord 2000;1:293-9.

19 EFNS Task Force on Diagnosis and Management of Amyotrophic Lateral Sclerosis Andersen PM, Abrahams $S$, et al. EFNS guidelines on the clinical management of amyotrophic lateral sclerosis (MALS) —revised report of an EFNS task force. Eur J Neurol 2012;19:360-75.

20 Banzett RB, O'Donnell CR, Guilfoyle TE, et al. Multidimensional Dyspnea Profile: an instrument for clinical and laboratory research. Eur Respir J 2015;45:1681-91.

21 Morélot-Panzini C, Gilet H, Aguilaniu B, et al. Real-life assessment of the multidimensional nature of dyspnoea in COPD outpatients. Eur Respir J 2016:47:1668-79.

22 Yanos J, Banner A, Stanko R, et al. Ventilatory responses to inspiratory threshold loading in humans. J App/ Physiol (1985) 1990;68:2511-20.

23 Georges M, Moraviec E, Raux M, et al. Cortical drive to breathe in amyotrophic lateral sclerosis: a dyspnoea-worsening defence? Eur Respir J 2016;47:1818-28.

24 Gui P, Ebihara S, Ebihara T, et al. Urge-to-cough and dyspnea conceal perception of pain in healthy adults. Respir Physiol Neurobiol 2012;181:214-19.

25 Raudenbush B, Koon J, Cessna T, et al. Effects of playing video games on pain response during a cold pressor task. Percept Mot Skills 2009;108:439-48.

26 Moont R, Pud D, Sprecher E, et al. 'Pain inhibits pain' mechanisms: is pain modulation simply due to distraction? Pain 2010;150:113-20.

27 Lewis GN, Heales L, Rice DA, et al. Reliability of the conditioned pain modulation paradigm to assess endogenous inhibitory pain pathways. Pain Res Manag 2012:17:98-102

28 Arendt-Nielsen L, Sluka KA, Nie HL. Experimental muscle pain impairs descending inhibition. Pain 2008;140:465-71.
29 Kindler LL, Sibille KT, Glover TL, et al. Drug response profiles to experimental pain are opioid and pain modality specific. J Pain 2011;12:340-51.

30 Bouhassira D, Chollet R, Coffin B, et al. Inhibition of a somatic nociceptive reflex by gastric distention in humans. Gastroenterology 1994;107:985-92.

31 Bouhassira D, Sabaté JM, Coffin B, et al. Effects of rectal distensions on nociceptive flexion reflexes in humans. Am J Physiol 1998;275(Pt 1):G410-17.

32 Similowski T, Attali V, Bensimon G, et al. Diaphragmatic dysfunction and dyspnoea in amyotrophic lateral sclerosis. Eur Respir I 2000;15:332-7.

33 Attali V, Mehiri S, Straus C, et al. Influence of neck muscles on mouth pressure response to cervical magnetic stimulation. Am J Respir Crit Care Med 1997;156 (Pt 1):509-14.

34 Hanisch F, Skudlarek A, Berndt J, et al. Characteristics of pain in amyotrophic lateral sclerosis. Brain Behav 2015;5:e00296.

35 Rivera I, Ajroud-Driss S, Casey P, et al. Prevalence and characteristics of pain in early and late stages of ALS. Amyotroph Lateral Scler Frontotemporal Degener 2013;14:369-72.

36 Pagnini F, Lunetta C, Banfi P, et al. Pain in Amyotrophic Lateral Sclerosis: a psychological perspective. Neurol Sci 2012;33:1193-6.

37 Wallace VC, Ellis CM, Burman R, et al. The evaluation of pain in amyotrophic lateral sclerosis: a case controlled observational study. Amyotroph Lateral Scler Frontotemporal Degener 2014;15:520-7.

38 Handy CR, Krudy C, Boulis N, et al. Pain in amyotrophic lateral sclerosis: a neglected aspect of disease. Neurol Res Int 2011;2011:403808.

39 Brettschneider J, Kurent J, Ludolph A. Drug therapy for pain in amyotrophic lateral sclerosis or motor neuron disease. Cochrane Database Syst Rev 2013;6: CD005226.

40 Pickering $G$, Jourdan D, Eschalier $A$, et al. Impact of age, gender and cognitive functioning on pain perception. Gerontology 2002;48:112-18. 